IZA DP No. 5056

Who Will Be Idol? The Importance of Social Networks for Winning on Reality Shows

Odelia Heizler

Ayal Kimhi

July 2010 


\title{
Who Will Be Idol? \\ The Importance of Social Networks for Winning on Reality Shows
}

\author{
Odelia Heizler \\ Hebrew University \\ and IZA
}

Ayal Kimhi

Hebrew University

\section{Discussion Paper No. 5056 \\ July 2010}

IZA

P.O. Box 7240

53072 Bonn

Germany

Phone: +49-228-3894-0

Fax: +49-228-3894-180

E-mail: iza@iza.org

Any opinions expressed here are those of the author(s) and not those of IZA. Research published in this series may include views on policy, but the institute itself takes no institutional policy positions.

The Institute for the Study of Labor (IZA) in Bonn is a local and virtual international research center and a place of communication between science, politics and business. IZA is an independent nonprofit organization supported by Deutsche Post Foundation. The center is associated with the University of Bonn and offers a stimulating research environment through its international network, workshops and conferences, data service, project support, research visits and doctoral program. IZA engages in (i) original and internationally competitive research in all fields of labor economics, (ii) development of policy concepts, and (iii) dissemination of research results and concepts to the interested public.

IZA Discussion Papers often represent preliminary work and are circulated to encourage discussion. Citation of such a paper should account for its provisional character. A revised version may be available directly from the author. 
IZA Discussion Paper No. 5056

July 2010

\begin{abstract}
Who Will Be Idol?

The Importance of Social Networks for Winning on Reality Shows ${ }^{*}$

This paper examines, both theoretically and empirically, the effect of social networks and belonging to minority groups (or race) on the probability of winning in reality television shows. We develop a theoretical model that studies viewer behavior by presenting a framework of competition between two contestants from two different groups. The results are examined empirically using unique contestant data from the highly popular reality show "A Star Is Born", the Israeli counterpart of "American Idol". Our main finding is that social networks and belonging to minority groups play key roles in the contestant's victory, but their effects are nonlinear: the social network effect is $U$-shaped, whereas that of belonging to a minority group follows an inverted $U$ shape. Beyond the world of reality TV, this paper sheds light on the general behavior of social networks as well.
\end{abstract}

JEL Classification: J15, D71, P16

Keywords: $\quad$ American Idol, social networks, minority groups, contest, voting

Corresponding author:

Odelia Heizler

Department of Agricultural Economics and Management

The Hebrew University

P.O. Box 12

Rehovot 76100

Israel

E-mail: ocohen@biu.013.net.il

\footnotetext{
"We are grateful to Klaus Zimmermann, Barry Chiswick, Carmel Chiswick, Amelie Constant, and other participants of the 6th IZA Annual Migration Meeting, for helpful and important comments.
} 


\section{Introduction}

"American Idol"- -based on the British TV show "Pop Idol", is the most popular and successful reality show on America's FOX TV network. "American Idol” is a singing competition, aimed at determining the best undiscovered young singers in the country. The judging system is democratic, with everyone being able to vote for his or her favorite contestant. In the 2007 season, "American Idol" drew a massive audience of 37.7 million viewers, peaking in the last half hour at more than 41 million viewers, and received a record 74 million votes. ${ }^{1}$ The "American Idol" format is successful worldwide. It has a plethora of spinoffs, including "Australian Idol”, "Canadian Idol”, "Indian Idol”, "Idols West Africa”, "Latin American Idol”, "New Zealand Idol”, "Pinoy Idol" (in the Philippines), and "A Star Is Born" (in Israel), to name a few.

Although the aim of "American Idol" and its counterparts is to find the most talented young singer in the country, viewer preferences may be affected by a variety of considerations beyond those of contestant ability or performance. The case of Sanjaya Malakar is an example of this: Malakar advanced to 7th place in season 6 of "American Idol" by getting the popular vote, despite poor reviews by the show's judges. One of those judges, Simon Cowell, threatened that if Malakar won, he would not return to judge the following show, even though he was contractually obligated to do so. Other competitors who won praises from the judges, like Antonella Barba, were eliminated in preliminary rounds. The British Rock star Elton John, once a guest judge on "American Idol", came right out with the claim that the voting by the national viewing audience was "incredibly racist". 2

Lee (2006) dealt with the question of whether the viewers of "American Idol" are racially biased by using ratings data from the first four seasons, 2002 through 2005. He found that the racial composition of the contestants affects the viewing of black and non-black households, such that as the share of black contestants increases, the black households' rating increases, whereas the non-black households' rating decreases. Lee (2006) also found strong evidence for same-race preferences in the

\footnotetext{
${ }^{1}$ Source: Wikipedia (http://en.wikipedia.org/wiki/American_Idol).

${ }^{2}$ According to Reuters, Source: http://au.news.yahoo.com/040427/11/oqwi.html.
} 
voting: a black contestant was less likely to be voted off when there were relatively more black viewers.

A vast number of economic and sociological studies have taken on the subject of same-race preferences (see, for example, Marshall, 1974; Holzer and Ihlanfeldt, 1998). Becker's pioneer study (1971) identified three principal sources of racial discrimination: discrimination by employers, discrimination by fellow workers, and discrimination by consumers. Becker discussed the issue of consumer discrimination directly reducing productivity, making it impossible to tell whether differential productivity is the effect of discrimination or of differential ability to do the job. Studies show that racial preferences or racial discrimination begin at a young age. Clark and Clark (1950) showed that 3- to 7-year-olds already had racial preferences: most of white skin children preferred dolls with white skin color and rejected dolls with brown skin color. They also found that the children's knowledge of the concept of racial difference had been established with the age. These racial preferences can then be expressed in choice of spouse, neighborhood, friends and even favorite TV show (see, for example, Wong, 2003).

Preferences for, or identification with specific contestants, irrespective of ability, can also be explained by social networks. There is a substantial body of economic and sociological literature on the important role played by social networks in human interactions and in communicating valuable information (see Bala and Goyal, 2000). This information may include, among other things, job and accommodation options, business opportunities, stock market tips and product quality. For example, Montgomery (1991) presented a long list of studies on the important role of social ties, such as friends and relatives, in job-search outcomes. Carrington et al. (1996) investigated the effect of social networks on immigrants' choice of location in their host country. A social network is created among two or more people with a common denominator, which can be broad (such as belonging to the same minority or religious group, or living in the same city) or narrow (such as learning in the same class, working in the same office).

Despite the development and enormous success of reality TV shows worldwide, to the best of our knowledge, there have not been any economics studies examining the relationship between social networks and viewers' behavior in reality TV shows, except for the aforementioned study by Lee (2006) on same-race preferences. The economics studies that do exist on reality shows investigate the structure and rules of 
the contest. For example, Amegashie (2007) studied the allocation of voting rights between the expert judges and the viewers on "American Idol", designed to prevent low-ability contestants from winning. He showed that the contestants' differences in ability should be an important consideration in the allocation of voting rights. Fu and $\mathrm{Lu}$ (2006) examined the optimal structure of multistage sequential-elimination contests and the optimal prize allocation, such as in "American Idol". They focused on the "winner-take-all" type of contest, i.e., a single winner and a single prize.

This paper starts by developing a theoretical model of competition between two different groups where each member decides how much effort to invest in favor of the contestant from his/her group. We study how the number of group members affects the strength of the relationship among the members. The effect of the benefit from the contestant's victory on the optimal effort is also examined. Our results are tested empirically using a unique dataset of contestants from the popular Israeli reality show "A Star Is Born", which is based on "American Idol". We distinguish between the behaviors of viewers from big cities and that of viewers from small areas, as well as between viewers from centrally located areas and those from the periphery.

Although this paper focuses on the effects of social networks and race on the behavior of reality-show voters, the results can be applied to a variety of situations, such as voter support of a candidate belonging to their minority group or who was born in their country. For example, Sen. Barak Obama, like the black leader Jesse Jackson in '84 and '88, recently beat Sen. Hillary Clinton in the racially charged state of South Carolina. About half of the voters were black and four out of five of them supported Obama. Obama got only a quarter of the white votes while Clinton and Sen. John Edwards split the rest. Obama declared that "The choice in this election is not about regions or religions or genders...it's not about black versus white," but it can be explained by our model on social networks and voter behavior.

This paper is organized as follows. Section 2 describes the analyzed reality show, "A Star Is Born". Section 3 displays a theoretical model of competition between two contestants from two different groups. Section 4 presents the empirical analysis which includes a description of the data, the method and the results. Section 5 concludes. 


\section{Background-“A Star Is Born"}

“A Star Is Born", which began its first season in 2003, is one of the most popular Israeli TV shows. "A Star Is Born”, like its counterpart "American Idol”, belongs to the new popular TV genre of reality shows. Reality shows are based on three main elements: 1) contestants are given a particular task; 2) at the completion of the task, the participants are critiqued; 3) one of the contestants is then eliminated from the competition (see Higdon, 2007). More than $31.2 \%$ of the Israeli population (35.9\% of the Jewish population) watched the final of the "A Star Is Born" competition in 2007. ${ }^{3}$ The number of votes in the final amounted to more than 900,000, as compared to about 3,186,000 votes in the country's general election in 2006.

Like "American Idol”, “A Star Is Born” begins with preliminary auditions in selected locations across Israel. Tens of thousands of candidates (about 40,000 in 2007) with the dream of becoming an idol are tested, interviewed and most are eliminated before the individual auditions in front of three main judges. The body of judges includes the best singers and artists; sometimes a fourth guest judge may be added. In the next stage, the judges choose an initial field of about 100 candidates and after a lengthy process, they narrow them down to a team of about 20 competitors. Although this top team is selected by expert judges, the viewers can marginally affect their decision by granting a "life-preserver" to selected candidates who were eliminated in the auditions, thereby returning them to the show.

When the auditioning stage is over, the power shifts from the expert judges to the viewers. The candidates sing solos and duets and deal with different musical genres, and the viewers are given a limited amount of time following each broadcast to vote for their favorite contestant via SMS from cellular phones or voting on the internet. Compared to "American Idol" which enables voting via a toll-free number, the voting for "A Star Is Born" costs 1 NIS per call. Another main difference between the rules of these two shows is that whereas in "American Idol" viewers are allowed to vote as many times as they like for any number of contestants, the voting in Israel is limited to five votes per voting method. ${ }^{4}$ The viewers can, of course, bypass this restriction by voting from different cellular phones and computers. The contestant

\footnotetext{
${ }^{3}$ Source: Wikipedia in Hebrew (www.he.wikipedia.org).

${ }^{4}$ This rule was not valid in the first three seasons, when the number of votes was limited to 250 .
} 
who obtains the lowest number of votes from the public is eliminated from the competition. In each show, one contestant is voted off, up until the quarter-finals when about eight contestants are left. Six of these contestants move on to the semifinals, where two groups of three contestants each compete. The winner of each group in the semi-finals moves on to the finals and a competition between the two secondplace contestants produce the third contestant in the finals.

During the season, the viewers can learn about the contestants' personalities, their hobbies, their resumes and their socioeconomic backgrounds via their blogs, official and unofficial websites, interviews and articles in magazines and newspapers, as well as from watching the show itself. The contestants' socioeconomic background and the minority groups to which they belong are emphasized in the media. Towards the finals, the viewers get a glimpse of the contestants' residences. On fan-based websites and the show's official website, among the reasons why one should vote for a specific individual we can easily find sentences such as: "I am voting for Daniel BenHaim because he lives in Migdal-Haemek," "I am not voting for Marina because she is Russian," or "All the people who come from Georgia must vote for Refael Mirela." Take the example of Miriam Tokan, the show's first Arabic contestant. Her being voted off spurred a widespread public debate on racist voting. Several articles were written on the topic, a central question being whether the show, which is a symbol of Israeli consensus, could afford to have an Arabic singer as its winner. The ArabIsraeli cabinet minister Raleb Majadele described Tokan as a young woman who overcame fear, broke the barriers and gave hope to all Arabic teenagers. In a letter to Tokan he wrote: "your angelic voice was a source of pride for me."

In every season of “A Star Is Born”, there have been spontaneous as well as formal public activities in favor of a specific contestant by his/her community for reasons unrelated to talent (see Neiger and Yosman, 2005). For example, the Ashkelon city council printed and displayed posters citywide which called for people to vote for Zipi Mashhid, a resident of that city. The city of Maale Edomim organized a campaign in favor of its resident, Arel Moyal: for the finals, the city gathered together dozens of teenagers to sit in the schools and vote the free 250 times for 
Moyal. ${ }^{5}$ The mayor explained that the city's support was in essence a way of thanking the contestant for the honor he had brought to the city. In the finals, Moyal overcame Skat, the contestant from Kfar Saba, who had led throughout the contest. Kfar Saba thought it enough to send emails reminding the city's workers to vote for Skat. The organizing of families, relatives and friends is also common: these groups may open "command centers" where each individual member contacts everybody he/she knows asking them to vote for the group's favorite contestant as many times as possible.

\section{The theoretical model}

Consider two reality-show contestants, $A$ and $B$, belonging to two different groups or from two different locations. The probability of each contestant winning depends on the relative number of votes he/she receives. Each group allocates resources and effort in favor of its contestant. Although rent-seeking models usually refer to interest groups that attempt to influence the outcomes of the political decision-making process in their favor via resource allocation (see for example, Appelbaum and Katz, 1987), here we adopt a standard model of rent seeking among interest groups.

Denote the number of group members for a contestant $i \forall i=A, B$ by $N_{i}$ and each member's effort in favor of that contestant by $E_{i}$. Hence the probability of contestant $i$ being the winner is given by:

$$
P_{i}=\frac{N_{i} E_{i}}{N_{i} E_{i}+N_{j} E_{j}}
$$

for $i \neq j$ and $j=A, B$.

It should be noted that this probability function is identical to Tullock's (1980) commonly used rule which claims that the probability of success in competition equals the relative effort. We treat belonging to a contestant's group as a club good

\footnotetext{
${ }^{5}$ The relative weight of those teenagers was high because most of the viewers, $73.9 \%$, chose to cast between 1 and 10 votes by each of the two routes whereas only $3 \%$ of them cast 250 votes via each of the two routes.
} 
that provides positive returns to the participants in the club (see Iannaccone, 1992). The decision of the group's members as to how much effort to invest in their contestant is affected by their benefit from his/her winning, $B_{i}$, which depends on the group's size, $N_{i}$, and the socioeconomic status of the group, $S_{i}$. As the group gets bigger, the relationship of the groups' members with the contestant weakens and their benefit from the candidate's victory, $B_{i}$, decreases, i.e. $\frac{d B_{i}\left(N_{i}, S_{i}\right)}{d N_{i}}<0{ }^{6}$; moreover, the lower the socioeconomic status of the group, the higher the benefit from the honor bestowed upon them by a victory, i.e. $\frac{d B_{i}\left(N_{i}, S_{i}\right)}{d S_{i}}<0$. The utility if the contestant loses the competition is normalized to zero. Our assumption may be supported by Narud and Share (1999) who found that party activists, belonging to extremist and small groups, invest more efforts in support of their candidates than activists belonging to larger groups, indicating that their utility from their candidate's victory is higher.

The expected net payoff for each member of group $i$ is given by:

$$
U_{i}=P_{i} B_{i}\left(N_{i}, S_{i}\right)-E_{i}
$$

We focus on the interior Nash equilibrium of the contest. The conditions characterizing this equilibrium are $\frac{\partial U_{i}}{\partial E_{i}}=0 \forall i=A, B$. From equations (1) and (2) it follows that the optimal effort of each member in group $i$ is given by:

$$
\frac{\partial U_{i}}{\partial E_{i}}=\frac{N_{i} N_{j} E_{j} B_{i}}{\left(N_{i} E_{i}+N_{j} E_{j}\right)^{2}}-1=0 .
$$

From equation (3), we get that at equilibrium, the optimal effort of each member of group $i \forall i=A, B$ equals:

\footnotetext{
${ }^{6}$ Suppose, for example, that the group contains only two people: if one of them wins the contest, the other will benefit from all honor and pride resulting from a victory.
} 


$$
E_{i}^{*}=\frac{N_{i} N_{j} B_{i}^{2} B_{j}}{\left(N_{i} B_{i}+N_{j} B_{j}\right)^{2}}
$$

for $i \neq j$ and $j=A, B$.

To determine the probability of the contestant from group $A$ being the winner at equilibrium, we plug equation (4) into equation (1):

$$
P_{i}^{*}=\frac{N_{i} \frac{N_{i} N_{j} B_{i}^{2} B_{j}}{\left(N_{i} B_{i}+N_{j} B_{j}\right)^{2}}}{N_{i} \frac{N_{i} N_{j} B_{i}^{2} B_{j}}{\left(N_{i} B_{i}+N_{j} B_{j}\right)^{2}}+N_{j} \frac{N_{i} N_{j} B_{j}^{2} B_{i}}{\left(N_{i} B_{i}+N_{j} B_{j}\right)^{2}}} .
$$

From equation (5), we find that the equilibrium probability of winning the contest is equal to:

$$
P_{i}^{*}=\frac{N_{i} B_{i}}{N_{i} B_{i}+N_{j} B_{j}} .
$$

This means that the probability of a contestant from group $i$ winning is equal to the sum of the benefits to group $i$ 's members from the victory of their contestant divided by the sum of the benefits to the two groups' members from the victory of their respective contestants.

Let us now examine the effect of the number of group members on the probability of winning. From equation (6):

$$
\frac{\partial P_{i}^{*}}{\partial N_{i}}=\frac{N_{j} B_{j}\left(B_{i}+N_{i} \frac{\partial B_{i}}{\partial N_{i}}\right)}{\left(N_{i} B_{i}+N_{j} B_{j}\right)^{2}} .
$$


The denominator of equation (7) is positive, but the numerator can be positive if $B_{i}>N_{i} \frac{\partial B_{i}}{\partial N_{i}}$ or negative if $B_{i}<N_{i} \frac{\partial B_{i}}{\partial N_{i}}$. To determine whether the extreme point is a minimum or maximum, we calculate the second derivative. We can obtain that:

$$
\frac{\partial^{2} P_{i}^{*}}{\partial N_{i}^{2}}=\frac{N_{j} B_{j}\left(\left(2 \frac{\partial B_{i}}{\partial N_{i}}+N_{i} \frac{\partial^{2} B_{i}}{\partial N_{i}^{2}}\right)\left(N_{i} B_{i}+N_{j} B_{j}\right)-2\left(B_{i}+N_{i} \frac{\partial B_{i}}{\partial N_{i}}\right)^{2}\right)}{\left(N_{i} B_{i}+N_{j} B_{j}\right)^{3}} .
$$

The last component in brackets in the numerator is clearly negative; in addition, we know that $\frac{\partial B_{i}}{\partial N_{i}}<0$, and thus the sign of $\frac{\partial^{2} P_{i}^{*}}{\partial N_{i}^{2}}$ depends on the sign of $\frac{\partial^{2} B_{i}}{\partial N_{i}^{2}}$. If $\frac{\partial^{2} B_{i}}{\partial N_{i}^{2}}<0$ then $\frac{\partial^{2} P_{i}^{*}}{\partial N_{i}^{2}}<0$ and the extreme point is a maximum; however, if $\frac{\partial^{2} B_{i}}{\partial N_{i}^{2}}>0$, the extreme point is a minimum if and only if $\frac{\partial^{2} B_{i}}{\partial N_{i}^{2}}>\frac{2\left(B_{i}+N_{i} \frac{\partial B_{i}}{\partial N_{i}}\right)^{2}}{N_{i}\left(N_{i} B_{i}+N_{j} B_{j}\right)}-\frac{2}{N_{i}} \frac{\partial B_{i}}{\partial N_{i}}$. Thus, the effect of a change in the number of group members on the probability of their contestant succeeding in the contest is determined by the rate of the effect of change in the number of group members on the benefit culled by each member if their contestant wins. It is known that as the number of group members increases, the strength of the relationship between them or their identification with the contestant decreases (i.e. $\frac{\partial B_{i}}{\partial N_{i}}<0$ ); however, the rate of that decrease is unknown.

We can conclude that:

\section{Proposition 1}

If $\frac{\partial^{2} B_{i}}{\partial N_{i}^{2}}<0 \quad$ or $\frac{\partial^{2} B_{i}}{\partial N_{i}^{2}}>0$ and $\left.\frac{\partial^{2} B_{i}}{\partial N_{i}^{2}}<\frac{2\left(B_{i}+N_{i} \frac{\partial B_{i}}{\partial N_{i}}\right)^{2}}{N_{i}\left(N_{i} B_{i}+N_{j} B_{j}\right)}-\frac{2}{N_{i}} \frac{\partial B_{i}}{\partial N_{i}}\right)$, then the relationship between the number of group members and the probability of winning has an inverted $U$ shape (Figure 1). 
If $\frac{\partial^{2} B_{A}}{\partial N_{A}^{2}}>0$ and is high enough (i.e. if $\frac{\partial^{2} B_{A}}{\partial N_{A}^{2}}>\frac{2\left(B_{A}+N_{A} \frac{\partial B_{A}}{\partial N_{A}}\right)^{2}}{N_{A}\left(N_{A} B_{A}+N_{B} B_{B}\right)}-\frac{2}{N_{A}} \frac{\partial B_{A}}{\partial N_{A}}$ ), then the relationship between the number of group members and the probability of winning has a U shape (Figure 2).

Next we examine the effect of the group's socioeconomic status on the probability of its contestant winning:

$$
\frac{\partial P_{i}^{*}}{\partial S_{i}}=\frac{N_{j} B_{j} N_{i} \frac{\partial B_{i}}{\partial S_{i}}}{\left(N_{i} B_{i}+N_{j} B_{j}\right)^{2}}
$$

Because $\frac{\partial B_{i}}{\partial S_{i}}<0$, it is clear that $\frac{\partial P_{i}^{*}}{\partial S_{i}}<0$, hence:

\section{Proposition 2}

There is a negative relationship between the socioeconomic status of the group and the probability of its contestant winning.

We expect that when the contestant belongs to a group characterized by low socioeconomic status, the benefit to the group members from his/her victory will be higher than for group members with high socioeconomic characteristics. This is because the victory brings the former group, which has a negative image, positive exposure and the hope that additional members will succeed, as in the aforementioned case of the Arabic contestant Miriam Tokan. Therefore, the members of this group will increase their efforts in support of their contestant.

Similarly, it is easy to see that $\frac{\partial P_{i}^{*}}{\partial B_{i}}=\frac{N_{j} B_{j}}{\left(N_{i} B_{i}+N_{j} B_{j}\right)^{2}}>0$. In words, there is a positive relationship between the benefit to the group's members from the victory of the contestant and his/her probability of winning. This result is supported by many studies which have shown that the player with the higher net payoff invests more resources in 
the contest and has a higher probability of winning the contest (see for example, Epstein and Nitzan, 2002).

\section{Empirical evidence}

\subsection{Summary statistics}

Following the theoretical model presented above, we examine the effect of social networks on the probability of winning a competition using unique data on the contestants of “A Star Is Born” for all five seasons, 2003 through 2007. Our dataset contains 103 individuals who reached the televised rounds, i.e. the rounds in which the audience participates in the judgment process. A listing of our data sources can be found in the Appendix.

The key explanatory variables in our analysis measure social networks. Following Bertrand et al (2000), Epstein et al. (2007) and others, we use two proxy variables to represent the social networks which exist within localities and within minority groups: the first is the number of residents in the contestant's location of residence, the second is the number of members in his/her minority group across Israel (if the contestant belongs to a minority group).In addition, the strength and width of social networks may vary by age, and teenagers also have more interest in reality TV programs than older people. Hence, we use the share of young people in the contestant's place of residence as another explanatory variable in the probability of success in the contest. From the theoretical model, it follows that as the viewers' benefit from their contestant winning increases, so will the effort they invest in $\mathrm{him} / \mathrm{her}$. We take the socioeconomic level of the contestant's location of residence as a proxy variable for the benefit incurred by the residents from their contestant winning, i.e., the lower the socioeconomic level of the location, the more negative press they receive, such as widespread unemployment, poverty, crime, etc. Therefore, the benefit to these residents from positive exposure in the media and the hope and honor brought about by a victory is higher than that to residents of a location with high socioeconomic level. We also control for other variables that may affect the probability of winning the contest, such as: gender, age and musical experience.

Table 1 displays summary statistics of the contestants and the characteristics of their locations of residence. About half of the contestants are male. Their average age 
is about 21.5 years. About $27 \%$ of the contestants served in the army's entertainment troop. It should be noted that the selection criteria for this unit are quite high and it has yielded many top Israeli singers. More than a quarter of the contestants have other (formal) musical experience, although the definition of what constitutes this experience is rather broad: some contestants have a wealth of experience performing at festivals, whereas some contestants sang in their school's choir; some contestants have been singing from a young age, whereas some began singing in front of audiences only a short time before the competition. Due to data limitations and the difficulty involved in quantifying the quality of the musical experience, we only use a dummy variable for other musical experience.

About a fifth of the contestants belong to minority groups which include: new immigrants from the former Soviet Union, new immigrants from Ethiopia, people with Yemenite origin, people with Georgian origin, national-religious men and Arabs. We define a contestant as belonging to a minority group only if it is discernible to the viewers by his/her name, behavior or other external signs (for example, the kippah traditionally worn by religious men). We define a contestant as an immigrant if he/she was born abroad and this can be discerned by the viewers, or his/her parents were born abroad and he/she has strong ties to this group, for example, by highlighting this in performances and singing ethnic music. ${ }^{7}$ The largest minority group is immigrants from the former Soviet Union, with about 930,000 people.

The variable Location size describes the number of residents in the contestant's residence location. The largest city is Jerusalem with about 450,000 residents and the smallest location is the regional council of Nahal Sorek, with about 2,400 residents. More than $40 \%$ of the contestants live in big cities, i.e. a city with more than 150,000 residents (this being the limit that affects the results). In our analysis, we were interested in the contestants' social networks relative to the other contestants in the same competition; we therefore used size of residence location as a percentile. The variable Location percentile describes the percentile of the location's size relative to the location sizes of the other contestants' residences in the same season. A particular

\footnotetext{
${ }^{7}$ For example, Boaz Mauda, the winner of season 5 (2007) and the representative of Israel in the Eurovision 2008, was nicknamed "the Yemenite cowboy" in the press - despite the fact that he was born in Israel - because of his appearance, his residence in a Yemenite enclave (moshav), his choice of ethnic songs and his strong ties to the Yemenite tradition.
} 
location's size percentile can differ from year to year. For instance, in the 2004 competition, the percentile of the city of Ashdod was 70, whereas it was the largest city in the 2006 competition (i.e. its percentile was set at 100).

The variable Socioeconomic cluster is an index of the socioeconomic level of a location, ranked from 1 to 10. This index is prepared by the Israeli Central Bureau of Statistics. It takes into account a variety of parameters such as: median age, average income per capita, unemployment rate, housing density, rate of households with computers, average number of cars per household, etc. The average socioeconomic cluster of the contestants' residence locations is around 6. Another variable is the Share of young people (aged 10-24 years) in the contestant's location of residence. It is assumed that young people have a greater interest in the singing competition, and therefore play a larger part in the voting than older people. The average share of young people is $26 \%$. Netivot leads in the list with more than $40 \%$ young people, whereas Givataim is in last place, with only $17 \%$.

\subsection{Method}

In the theory section we modeled the probability of winning. This is however too simplistic for our empirical application. The reason is that the contest is conducted in several stages. In each stage, some of the contestants advance to the next stage, while the others are eliminated. Therefore, we choose as a dependent variable the highest stage of the competition reached by the contestant. We would have preferred to use the number (or percent) of votes received by each contestant, but these data are not available: we only know who obtains the fewest votes and is eliminated. Of course, as the contestant survives more rounds, the implication is that he/she has more votes than the contestants who are voted off. Hence, we treat the number of votes as a latent continuous variable that determines the probability of winning (as in the theoretical model) as well as the highest stage achieved (as in the empirical application).

Table 2 presents two possible divisions into stages, with each stage including the value of the dependent variable and the percentage of observations. The first possibility is division into six stages: first place, second place, third place, semi-final, quarter-final and others. The second division possibility consists of three stages: takes part in the final (i.e., the three top places), takes part in the semi-final or quarter-final, and others. The first division possibility has two main problems: in "A Star Is Born", the judges can grant "immunity" to one contestant per round until the semi-finals (if 
there is consensus among the judges). This means that this contestant will move on to the next round even if he/she receives the lowest number of votes. This can marginally affect the results because sometimes the "immune" contestant is the one that would have otherwise been eliminated. ${ }^{8}$ Moreover, the weight of the judges' score in the finals and semi-finals is $25 \%$ ( $75 \%$ being the share of the viewer votes), and thus the judges can influence the order of the three finalists. Unfortunately, we do not have accurate information on the contestants' rankings without the judges' scores. The second problem in the first division possibility is scarcity of observations for the first three places, i.e., amounting to less than 5\% (see Table 1); however, if we refer to this group as one category, it contains almost $15 \%$ of the observations. We therefore adopt the second division possibility, i.e. division into three stages.

Ordered Logit models are used to estimate the relationship between the stage reached by the contestant and a set of independent variables (see Greene, 2002). The Ordered Logit model specifies the probability of observing outcome $i$ as the probability that a linear function of explanatory variables plus a random error, is within the range of the cut points estimated for the outcome:

$$
\operatorname{Pr}\left(\text { outcome }_{j}=i\right)=\operatorname{Pr}\left(k_{i-1}<\beta_{1} x_{1 j}+\beta_{2} x_{2 j}+\ldots+\beta_{k} x_{k j}+u_{j} \leq k_{i}\right), i=1, \ldots, I
$$

where $u_{j}$ is assumed to be logistically distributed. In either case, the coefficients $\beta_{1}, \beta_{2}, \ldots, \beta_{k}$ along with the cut points, $k_{1}, k_{2}, k_{I-1}$ are estimated, where $I$ is the number of possible outcomes, $k_{0}$ is taken as $-\infty$ and $k_{I}$ as $+\infty$.

The estimated coefficients of the Ordered Logit model cannot be readily interpreted. They represent marginal effects of each variable on the unobserved latent variable from which the ordered outcomes are derived should be estimated, but these marginal effects are conditional on normalizing the error variance to 1 . Hence, we will refer to the signs of these marginal effects rather than on their magnitude.

The data is composed of observations on contestants from five consecutive seasons; this gives rise to the possibility that the standard errors are correlated within

\footnotetext{
${ }^{8}$ For example, in season 5 (2007), Alisa Shparaga rose to the semi-finals only thanks to "immunity" from the judges.
} 
each season. We therefore derive cluster-robust standard errors for the statistical inference.

\subsection{Results}

Table 3 presents the results. Due to correlation between the variables Location size and Minority group size, we run segregated regressions with each social network's variable in columns (1) and (2). Column (3) displays the regression with both variables. As expected from our theoretical model, we find that the effect of social network variables on the level of success in the competition is not linear - the variables behave differently: the minority group size has an inverted U-shaped effect on the probability of winning in the contest whereas the location size has a U-shaped effect on this probability. The inverted $U$ and $U$ shapes are retained in the combined regression in column (3), but the significance decreases because of the correlation. Our results indicate that the size of the minority group increases the level of success as long as it is lower than about 550,000, and decreases the level of success above this cutoff point. Hence, contestants from "medium-size" minorities have a higher level of success relative to contestants from smaller or bigger minority groups. The Increasing location percentile decreases the probability of winning as long as it is below $65 \%$, and increases the probability above that cutoff, such that contestants from the biggest and smallest locations have better chances of winning the contest.

The location's socioeconomic cluster has a significant effect only in big cities (i.e. city with 150,000 residents or more). ${ }^{910}$ As expected, its effect is negative, i.e. contestants from big cities have a higher probability of winning the contest as the socioeconomic level of their location decreases. The variable Share of young people also has a significant and positive effect only in big cities. ${ }^{11}$ The fact that these variables are significant only for big cities can be explained as follows: in big cities,

\footnotetext{
${ }^{9}$ When we estimated the regression with the variables socioeconomic cluster, Share of young people, and their interactions with big cities, the results does not change qualitatively.

${ }^{10}$ We examined the existence of different effects of economic cluster and share of young people in big versus small locations, but we found a significant effect only for big locations.

${ }^{11}$ As explained in the Appendix, this variable is based on the 1995 population census (the most recent Israeli census), so it may not precisely represent today's situation. However, the essence of the results did not change when we left this variable out.
} 
the probability of a viewer from the contestant's residence location knowing the contestant (or his/her family) personally is rather small, and the feeling of membership and identification with the contestant is weak. If the viewer votes for a contestant from his/her location, he/she is probably doing so to benefit from that contestant's becoming the winner. The lower the socioeconomic level of the location, the greater the viewer's benefit from positive advertisement and from the consequent hope that people from this location will succeed in the future; however, in small locations, the personal connection with the contestant (or his/her extended family) and the identification with him/her is stronger than in big cities. Hence, people will invest effort in their contestant, even if the benefit from positive advertisement is low. Moreover, people in small locations will invest effort in their contestant even if they are adults and reality TV shows interest them less than they interest young people.

The variable age is not significant in any of the regressions. Note that its variance is rather small (table 1); while the average age is $21.5,80 \%$ of the contestants are aged 23 years or younger. Note that the rules of the contest determine a lower age limit, 16 years, but there is no upper limit (as opposed to "American Idol" which imposed an upper age limit of 24 years, which was then increased to 28 years). Nevertheless, the judges actually tend to select the younger contestants in the early auditions. Regarding gender, the judges and the show's producers try to prevent a situation in which all the finalists are males or females via some tools they have at their disposal (for example, dividing the contestants into two semi-finalist groups, granting "immunity", the "life-preserver" option which returns contestants who were voted off the program, etc.). Hence, our regressions do not include the variable Gender. $^{12}$

As expected, serving in the army's entertainment troop affects the prospects of success in the contest significantly and positively. However, surprisingly, the dummy variable of other musical experience is not significant. This can be explained by the broad definition of this variable: some contestants have a wealth of musical experience, whereas some have very little, but we cannot distinguish between them. Another explanation is that the viewers prefer to vote for previously unknown singers. Table 4 presents the results when the dependent variable is divided into six stages. As mentioned above, this division is somewhat problematic because of the judges'

\footnotetext{
${ }^{12}$ The essence of the results does not change even if we include this variable.
} 
potential marginal effect on the stage a particular contestant reaches and because of the scarcity of observations for the top three places. However, we can see that the essence of the results does not change using this division.

\section{Discussion}

This paper has studied the effect of social networks of contestants on his probability of winning the contest, both theoretically and empirically. We examined two kinds of social networks: those based on the contestant's place of residence and those based on minority groups if the contestant belongs to such a group. Our theoretical results show that the social networks' behavior depend on the rate of the effect of change in the number of contestant's group members on the benefit culled by each member if their contestant wins and on the socioeconomic status of the contestant's group.

We used contestant data from the highly popular reality show "A Star Is Born”, the Israeli counterpart of "American Idol". We found that the effect of social network variables on the probability of winning the competition is not linear: the minority group size has an inverted U-shaped effect on the probability of winning the contest, whereas the location size has a U-shaped effect on this probability. This means that the size of the minority group initially increases the probability of winning and afterward decreases it, whereas the location size initially decreases the probability of winning and afterward increases it. We also found that the socioeconomic status of the contestant's group significantly decreases the probability of winning the contest, but only for contestants from big cities.

In this paper, we identified a number of significant attributes of social networks, related to voting in reality TV shows. While reality shows have become central and important in the culture and leisure life of millions across the world, there are almost no studies on the behavior of those people. Our theoretical model of the optimal effort of the individual in favor of his favorite contestant has been applied to the case of reality shows, but it can be applied to various other cases, such as membership in sport clubs, membership in church groups, supporting political candidates, etc. 


\section{References}

Amegashie, J.A. (2007): American Idol: Should it Be a Singing Contest or a Popularity Contest? CESifo Working Paper Series No. 2171.

Appelbaum, E. and Katz, E. (1987): "Seeking Rents by Setting Rents: The Political Economy of Rent Seeking," The Economic Journal, 97(387), pp. 685-699.

Bala, V. and Goyal, S. (2000): “A Strategic Analysis of Network Reliability," Review of Economic Design, 5, pp. 205-228.

Becker, G.S. (1971): The Economics of Discrimination. Chicago: The University of Chicago Press.

Bertrand, M., Luttmer, E.F.P. and Mullainathan, S. (2000): "Network Effects and Welfare Cultures," The Quarterly Journal of Economics, 115(3), pp. 1019-1055.

Carrington, W.J., Detragiache, E. and Vishwanath, T. (1996): "Migration with Endogenous Moving Costs," American Economic Review, 86(4), pp. 909-930.

Clark, K.B. and Clark, M.P. (1950): "Emotional Factors in Racial Identification and Preference in Negro Children," The Journal of Negro Education, 19(3), pp. 341-350.

Bauer, T. Epstein, G.S. and Gang, I.N. (2007): "The Influence of Stocks and Flows on Migrants' Location Choices," Research in Labor Economics, 2007, 26, 199-229.

Epstein, G.S. and Nitzan. S. (2002): "Asymmetry and Corrective Public Policy in Contests," Public Choice, 113(1-2), pp. 231-240.

Fu, Q. and Lu, J. (2006): “The Optimal Multi-Stage Contest”, MPRA Paper No. 946, http://mpra.ub.uni-muenchen.de/946/

Greene, W.H. (2002): Econometric Analysis (Fifth Edition). New Jersey: Prentice Hall.

Higdon, M.J. (2007): "From Simon Cowell to Tim Gunn: What Reality Television Can Teach Us About How to Critique our Students' Work Effectively," Perspectives: Teaching Legal Research and Writing, 15(3), pp. 169-173.

Holzer, H.J. and Ihlanfeldt, K.R. (1998): "Customer Discrimination and Employment Outcomes for Minority Workers," The Quarterly Journal of Economics, 113(3), pp. 835-867.

Iannaccone, L.R. (1992): "Sacrifice and Stigma: Reducing Free-riding in Cults, Communes, and Other Collectives," Journal of political Economy, 100(2), pp. 27191.

Lee, J. (2006): American Idol: Evidence of Same-Race Preferences? IZA Discussion Paper No. 1974, Bonn: IZA,. www.iza.org. 
Marshall, R. (1974): “The Economics of Racial Discrimination: A Survey," Journal of Economic Literature, 12(3), pp. 849-871.

Montgomery, J.D. (1991): "Social Networks and Labor-Market Outcomes: Toward an Economic Analysis," American Economic Review, 81(5), pp. 1408-1418.

Narud, H.M. and A. Share (1999): "Are Party Activist the Party Extremists? The Structure of Opinion in Political Parties", Scandinavian Political Studies, 22(1), pp. 45-65.

Neiger, M. and Yosman, A. (2005): "The Illusion of Democratic Choice: How the Reality Shows Achieve Cooperation of Viewers," Chaim Herzog Institute for Media, Politics and Society, Booklet 3. (in Hebrew) www.tau.ac.il/institutes/herzog.

Tullock, G. (1980): "Efficient rent-seeking". In Buchanan, J.M., Tollison, R.D. and Tullock, G., Toward a Theory of the Rent-Seeking Society. College Station: Texas A \& M University Press, pp. 97-112.

Wong, L.Y. (2003): "Why Do Only 5.5\% of Black Men Marry White Women?" International Economic Review, 44(3), pp. 803-826. 
Figure 1. Inverted U-shaped probability of winning
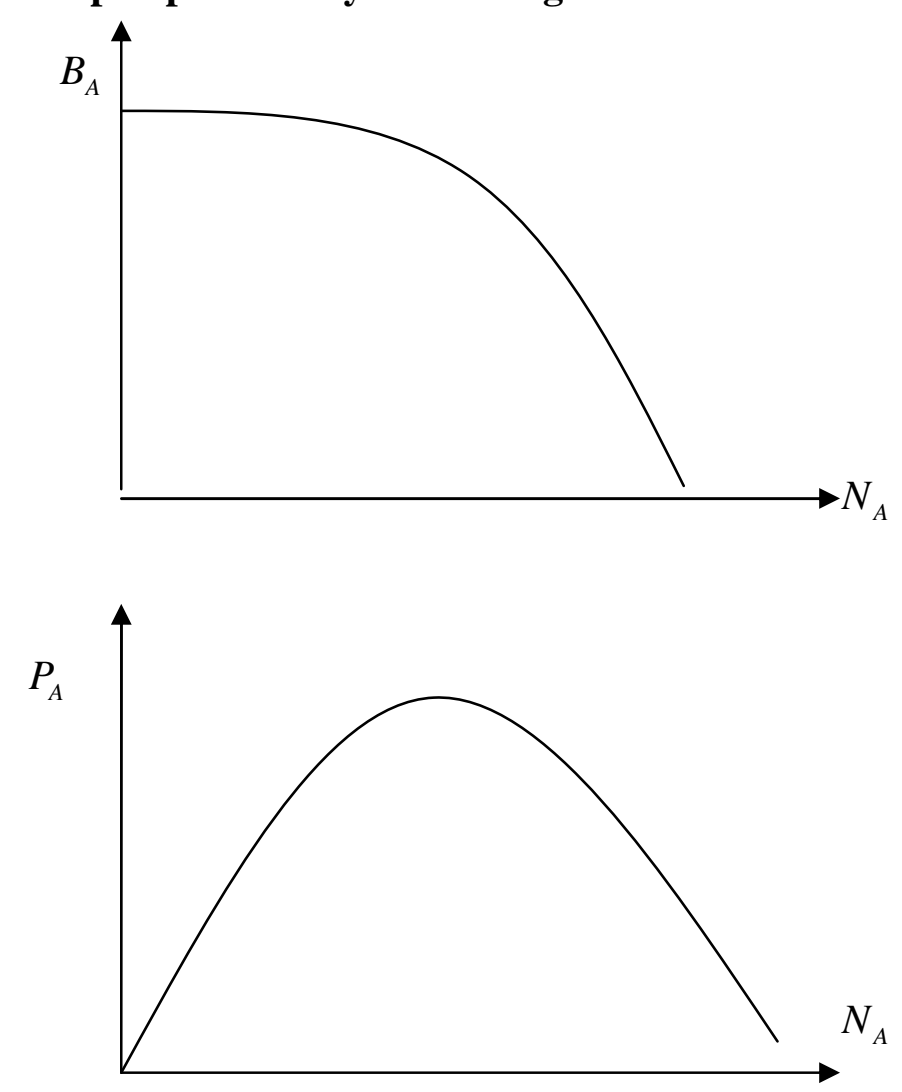
Figure 2. U-shaped probability of winning
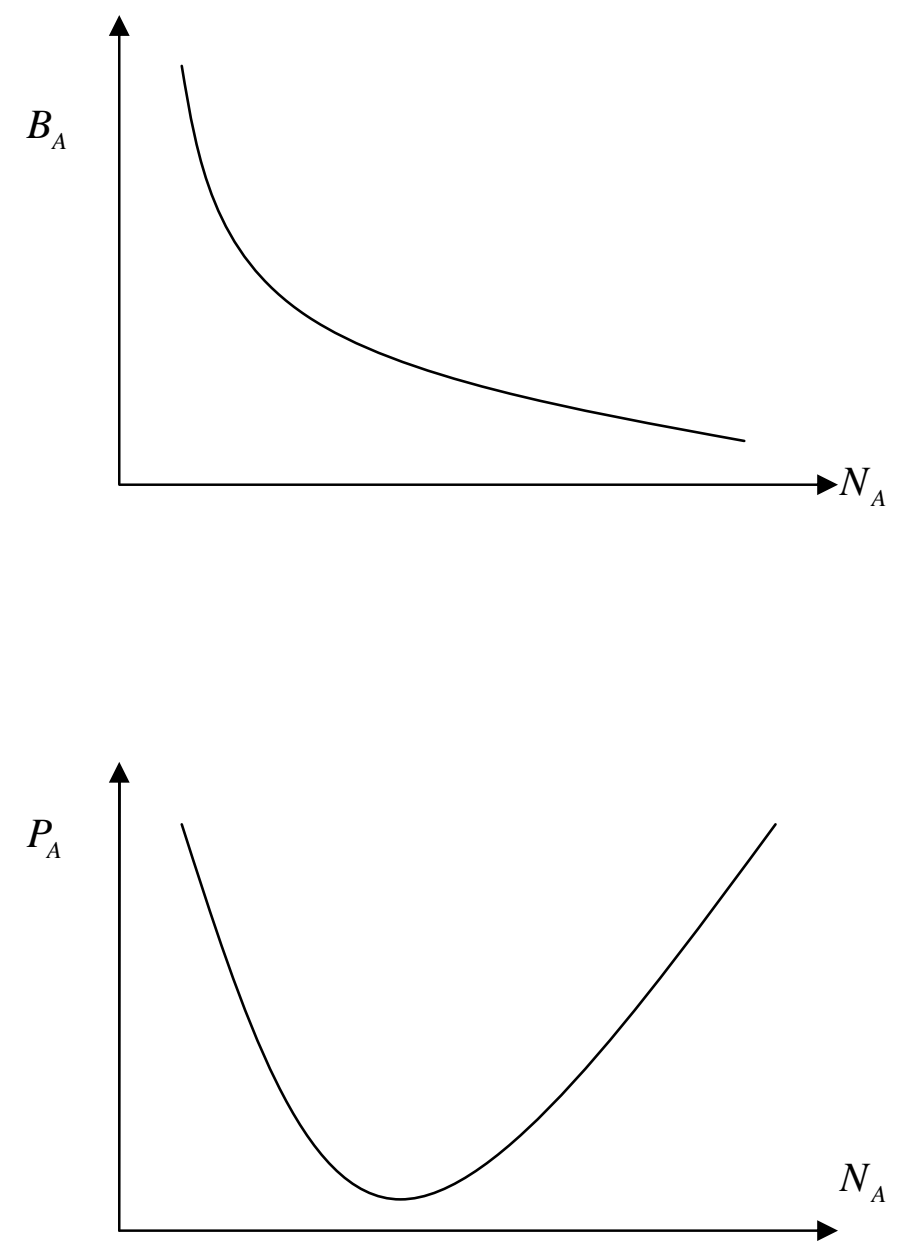
Table 1. Explanatory Variables and Descriptive Statistics

\begin{tabular}{|c|c|c|c|c|}
\hline \multicolumn{5}{|l|}{ Quantitative variables: } \\
\hline Variable & Mean & Std. Dev. & Min & Max \\
\hline Age & 21.446 & 2.757 & 16 & 30 \\
\hline Minority group size (in 100,000 ) & 0.933 & 2.548 & 0 & 9.26420 \\
\hline Location size (in 100,000) & 1.3236 & 1.1462 & 0.024 & 4.537 \\
\hline Location percentile & 0.544 & 0.296 & 0.05 & 1 \\
\hline Socioeconomic cluster & 6.077 & 1.569 & 3 & 10 \\
\hline Share of young people & 0.262 & 0.055 & 0.17 & 0.412 \\
\hline \multicolumn{5}{|l|}{ Dummy variables: } \\
\hline \multicolumn{5}{|l|}{ Gender $(\%)$} \\
\hline & \multirow{2}{*}{$\begin{array}{l}\text { Male } \\
\text { Female }\end{array}$} & \multirow{2}{*}{\multicolumn{3}{|c|}{$\begin{array}{l}50.49 \\
49.51\end{array}$}} \\
\hline Female & & & & \\
\hline \multicolumn{5}{|l|}{ Army entertainment troop (\%) } \\
\hline Yes & & \multirow{2}{*}{\multicolumn{3}{|c|}{$\begin{array}{l}27.18 \\
72.82\end{array}$}} \\
\hline No & & & & \\
\hline \multicolumn{5}{|l|}{ Other musical experience $(\%)$} \\
\hline Yes & & \multirow{2}{*}{\multicolumn{3}{|c|}{$\begin{array}{l}25.24 \\
74.76\end{array}$}} \\
\hline No & & & & \\
\hline \multicolumn{5}{|l|}{ Minority groups (\%) } \\
\hline \multirow{2}{*}{\multicolumn{2}{|c|}{$\begin{array}{l}\text { Yes } \\
\text { No }\end{array}$}} & \multicolumn{3}{|l|}{18.45} \\
\hline & & \multicolumn{3}{|l|}{81.55} \\
\hline \multicolumn{5}{|l|}{ Big city $(\%)$} \\
\hline \multicolumn{2}{|l|}{ Yes } & \multicolumn{3}{|l|}{42.72} \\
\hline \multicolumn{2}{|l|}{ No } & \multicolumn{3}{|l|}{57.28} \\
\hline
\end{tabular}


Table 2. The Dependent Variable

\begin{tabular}{|l|c|c|c|c|}
\hline \multirow{2}{*}{ Stage } & \multicolumn{2}{|c|}{ Six stages } & \multicolumn{2}{c|}{ Three stages } \\
\cline { 2 - 4 } & Value & $\begin{array}{c}\text { Percent of } \\
\text { observations }\end{array}$ & Value & $\begin{array}{c}\text { Percent of } \\
\text { observations }\end{array}$ \\
\hline $\begin{array}{c}\text { First place (takes part } \\
\text { in the final) }\end{array}$ & 6 & $4.85 \%$ & 3 & $14.56 \%$ \\
\hline $\begin{array}{c}\text { Second place (takes } \\
\text { part in the final) }\end{array}$ & 5 & $4.85 \%$ & & \\
\hline $\begin{array}{c}\text { Third place (takes part } \\
\text { in the final) }\end{array}$ & 4 & $4.85 \%$ & 2 & $30.10 \%$ \\
\hline $\begin{array}{c}\text { Semi-final } \\
\text { Quarter-final }\end{array}$ & 2 & $16.5 \%$ & & \\
\hline Others & 1 & $55.34 \%$ & 1 & $55.34 \%$ \\
\hline
\end{tabular}


Table 3. Ordered Logit Estimation of the Highest Stage Achieved in the Competition (out of Three Stages),

\begin{tabular}{|c|c|c|c|}
\hline Independent variables: & (1) & (2) & (3) \\
\hline Minority group size & $\begin{array}{l}1.279 * * * \\
(6.15)\end{array}$ & - & $\begin{array}{l}1.092^{* * * *} \\
(3.67)\end{array}$ \\
\hline$(\text { Minority group size })^{2}$ & $\begin{array}{c}-0.116^{* * * *} \\
(-4.17)\end{array}$ & - & $\begin{array}{c}-0.0964 * * \\
(-2.52)\end{array}$ \\
\hline Location percentile & - & $\begin{array}{c}-7.878 * * * \\
(-4.13)\end{array}$ & $\begin{array}{c}-5.674 * * * \\
(-2.78)\end{array}$ \\
\hline${\text { (Location percentile })^{2}}^{2}$ & - & $\begin{array}{l}5.981 * * * \\
(3.37)\end{array}$ & $\begin{array}{l}3.778 * * \\
(2.56)\end{array}$ \\
\hline $\begin{array}{l}\text { Socioeconomic cluster*Big } \\
\text { city }\end{array}$ & $\begin{array}{c}-0.534 * * * \\
(-3.10)\end{array}$ & $\begin{array}{c}-0.555 * * * \\
(-3.24)\end{array}$ & $\begin{array}{c}-0.500 * * \\
(-2.43)\end{array}$ \\
\hline $\begin{array}{l}\text { Share of young people*Big } \\
\text { city }\end{array}$ & $\begin{array}{c}8.873 * * \\
(2.00)\end{array}$ & $\begin{array}{l}11.074 * * * \\
(2.92)\end{array}$ & $\begin{array}{l}10.379 * * \\
(2.54)\end{array}$ \\
\hline Age & $\begin{array}{l}-0.005 \\
(-0.09)\end{array}$ & $\begin{array}{l}-0.088 \\
(-1.02)\end{array}$ & $\begin{array}{l}-0.060 \\
(-0.77)\end{array}$ \\
\hline Army entertainment troop & $\begin{array}{l}1.324 * * * \\
(3.25)\end{array}$ & $\begin{array}{l}1.238 * * \\
(2.14)\end{array}$ & $\begin{array}{l}1.461 * * * \\
(2.86)\end{array}$ \\
\hline Other experience & $\begin{array}{l}0.516 \\
(0.86)\end{array}$ & $\begin{array}{l}0.456 \\
(0.72)\end{array}$ & $\begin{array}{l}0.488 \\
(0.83)\end{array}$ \\
\hline Wald $\chi^{2}$ & 16.43 & 37.33 & 14.13 \\
\hline Prob $>\chi^{2}$ & 0.002 & 0.000 & 0.006 \\
\hline Pseudo $R^{2}$ & 0.163 & 0.119 & 0.183 \\
\hline Number of observations & 103 & 103 & 103 \\
\hline
\end{tabular}

Notes:

1. Cluster-robust $Z$ values are denoted in parentheses.

2. $* * *, * * *$ denote significance at 1,5 and 10 percent, respectively. 
Table 4. Ordered Logit Estimation of the Highest Stage Achieved in the Competition (out of Six Stages),

\begin{tabular}{|c|c|c|c|}
\hline Independent variables: & (1) & (2) & (3) \\
\hline Minority group size & $\begin{array}{c}1.150 * * * \\
(3.85)\end{array}$ & - & $\begin{array}{c}1.015^{* * * *} \\
(2.72)\end{array}$ \\
\hline$(\text { Minority group size })^{2}$ & $\begin{array}{c}-0.101 * * * \\
(2.70)\end{array}$ & - & $\begin{array}{c}-0.087 * \\
(-1.88)\end{array}$ \\
\hline Location percentile & - & $\begin{array}{c}-6.950 * * * \\
(-3.19)\end{array}$ & $\begin{array}{l}-5.312 * * \\
(-2.50)\end{array}$ \\
\hline (Location percentile) $^{2}$ & - & $\begin{array}{l}5.412 * * * \\
(2.74)\end{array}$ & $\begin{array}{l}3.636 * * * \\
(2.58)\end{array}$ \\
\hline $\begin{array}{l}\text { Socioeconomic cluster*Big } \\
\text { city }\end{array}$ & $\begin{array}{c}-0.465 * * * \\
(-2.77)\end{array}$ & $\begin{array}{c}-0.504 * * * \\
(-3.02)\end{array}$ & $\begin{array}{c}-0.428 * * \\
(-2.10)\end{array}$ \\
\hline $\begin{array}{l}\text { Share of young people*Big } \\
\text { city }\end{array}$ & $\begin{array}{l}7.306^{*} \\
(1.65)\end{array}$ & $\begin{array}{c}9.629 * * * \\
(2.60)\end{array}$ & $\begin{array}{c}8.443 * * \\
(2.07)\end{array}$ \\
\hline Age & $\begin{array}{l}-0.005 \\
(-0.08)\end{array}$ & $\begin{array}{l}-0.081 \\
(-1.02)\end{array}$ & $\begin{array}{l}-0.057 \\
(-0.86)\end{array}$ \\
\hline Army entertainment troop & $\begin{array}{c}1.159 * * \\
(2.28)\end{array}$ & $\begin{array}{l}0.993 \\
(1.62)\end{array}$ & $\begin{array}{l}1.270 * * \\
(2.30)\end{array}$ \\
\hline Other experience & $\begin{array}{l}0.454 \\
(0.94)\end{array}$ & $\begin{array}{l}0.386 \\
(0.73)\end{array}$ & $\begin{array}{l}0.422 \\
(0.92)\end{array}$ \\
\hline Wald $\chi^{2}$ & 11.19 & 84.78 & 41.44 \\
\hline Prob $>\chi^{2}$ & 0.024 & 0.000 & 0.000 \\
\hline Pseudo $R^{2}$ & 0.111 & 0.073 & 0.124 \\
\hline Number of observations & 103 & 103 & 103 \\
\hline
\end{tabular}

Notes:

1. Cluster-robust $\mathrm{Z}$ values are denoted in parentheses.

2. $* * *, * * *$ denote significance at 1,5 and 10 percent, respectively. 


\section{Appendix-data sources}

\section{Personal data on the contestants}

Personal data on the contestants such as: gender, age, residence, musical experience, belonging to minority groups and the stage that he/she reached in the competition were collected from the official website of "A Star Is Born”, fan websites, personal websites, contestant blogs and watching the programs. The official website of "A Star Is Born" only contains full details on the contestants from seasons 4 and 5 (years 2006-2007) and was used as the basis for data on the contestants from those seasons. The data on contestants from earlier seasons were collected from the other mentioned sources.

The main websites from which the data were drawn are:

Official website of "A Star Is Born 5":

http://www.keshet-tv.com/Starborn5/Default.aspx

Official website of "A Star Is Born 4":

http://www.keshet-tv.com/Starborn4/Default.aspx

Links to contestants personal websites:

http://index.nana10.co.il/category.asp?cat=3144

Details on season 3 contestants:

http://www.tve.co.il/mini.asp?id=31

Details on season 2 contestants:

http://www.tapuz.co.il/blog/userBlog.asp?FolderName=KohavNolad2

Details on season 1 contestants:

http://mooma.keshet-tv.com/Discs.asp?ArtistID=29\&AlbumID=39331

\section{Data on residence location and minority group characteristics}

- The number of residents in a locality and the minority group sizes were obtained from the Central Bureau of Statistics, Statistical Abstract of Israel for the years 2003-2007.

- The socioeconomic clusters of residence localities were collected from the Central Bureau of Statistics, Characterization and Classification of Local Authorities by the Socioeconomic Level of the Population, 2003. 
- The share of young people was collected from the Central Bureau of Statistics, Population and Housing Census, 1995. Due to the lack of other data on the share of young people, we used the share of children aged 0-14 years at the time of the census as a proxy for young people aged 10-24 at the time of the competition. 